\title{
Do the clinical findings correlate with the severity of the pneumonia in foals?
}

\author{
Juliane Fels', Karl Rohn² and Monica Venner ${ }^{3}$ \\ 1 University of Veterinary Medicine Hannover, Clinic for Horses, Hanover, Germany \\ 2 University of Veterinary Medicine Hannover, Institute for Biometry, Epidemiology and Information Processing, Hanover, Germany \\ ${ }^{3}$ Equine Clinic Destedt, Destedt, Germany
}

\begin{abstract}
Summary: Bronchopneumonia in horse-breeding plays a major role in the first few months of life in foals. The disease occurs worldwide and as prevention is difficult, early diagnosis and adequate monitoring are important in order to reduce losses. The actual study is expected to determine clinical parameters that indicate a worsening of pneumonia early in order to facilitate the monitoring of sick foals and to analyse the relationship between age at diagnosis, severity of the disease and prognosis. The prospective clinical study was designed four groups of foals with pulmonary lesions of different severity. The foals were monitored for two weeks after diagnosis. A subclinical or clinical pneumonia was diagnosed in 465 foals by means of ultrasonographic examination of the lung. Foals with findings in the ultrasonographic examination were tested at random for bacterial pathogens by microbiological culture. Tracheobronchial aspirates were sampled via endoscope. Clinical examination (rectal temperature, auscultation of trachea and lungs) and ultrasonographic examination of the lung were performed weekly for the two weeks following the day of diagnosis. A total of 135 foals had small pulmonary lesions and received no antibiotic treatment, 221 foals had a mild and were treated with sulfadiazine-trimethoprim, 92 foals had a moderate, they were treated with rifampin and tulathromycin and 66 foals a severe pneumonia, which were treated with rifampin and azithromycin. Of all 53 foals sampled for airway pathogens, in 14 foals Rhodococcus equi was isolated and in 40 foals Streptococcus equi zooepidemicus was identified. All recovered fully within a maximum of 9.5 weeks of treatment; 47 foals with mild to severe pneumonia needed a change of treatment, because the first choice of antibiotics failed to cure the foals. Fever was observed in $23 \%$ of the foals with small pulmonary lesions, which is significantly less $(p<0.0001)$ than in the $60 \%$ of foals with severe pneumonia. Auscultation findings in the lung and trachea were more frequent with the increasing severity of the pneumonia, but significantly different only between groups 1 and $4(p<0.018)$. The average age at diagnosis in all groups was 102 days, but foals which needed a change of treatment were significantly younger (80 days; $p<0.0001$ ). Regarding the three signs studied, fever is the best indicator of a more severe progression of disease and worsening of the pneumonia that leads to a change of treatment. The age of foals at diagnosis showed no difference regarding the severity of ultrasonographic findings, but foals that needed a change of antibiotics were significantly younger than the others. Therefore, young foals with pneumonia need to be monitored closely, even if the age at diagnosis did not correlate with the severity of the pneumonia.
\end{abstract}

Keywords: foal, pneumonia, clinical parameter, examination, age, diagnosis

Citation: Fels, J., Rohn, K., Venner, M. (2020) Do the clinical findings correlate with the severity of pneumonia in foals? Pferdeheilkunde 37, 147-155; DOI 10.21836/PEM20210206

Correspondence: PD Dr. Monica Venner PhD, Equine Clinic, Trift 4, 38162 Destedt, Germany; mvenner@gmx.de

Submitted: December 20, 2020

Accepted: February 5, 2021

\section{Introduction}

Abscessing bronchopneumonia in foals is one of the most frequent diseases in horse-breeding worldwide. The pulmonary disorder with abscessation and consolidation of the lung in foals has been the subject of many studies since it was first mentioned almost 100 years ago. The most common pathogens for pneumonia are Streptococcus equi ssp. zooepidemicus (Strep. zoo. (Hoffman 1993)) and Rhodococcus equi (R. equi), while other bacteria and viruses can cause pneumonia in foals, but are detected less frequently (Lavoie et al. 1994). Strep. zoo. is a normal colonizer of the upper respiratory tract in horses and is often implicated in pulmonary disorders (Hartung 2018, Lavoie et al. 1994). Next to pneumonia, Strep. zoo. can be the cause of pharyngitis and umbilical and wound infections (Lorenz et al. 2006) and is a near relative to the strangles-pathogen Streptococcus equi ssp. equi (Timoney
2004). R. equi is a soil inhabitant and found in the manure of foals and adult horses (Takai et al. 1986). The age, at which foals develop $R$. equi pneumonia, is from two to six months old and different sources have described an accumulation until the third or fourth month of age (Falcon 1985, Muscatello 2012).

The diagnosis of pneumonia in foals might appear difficult because of the subclinical development and the high compensation capacity of the lung (Giguere and Prescott 1997). When clinical signs are noticed, the majority of sick foals show pulmonary lesions that suggest a chronic course, which leads to the assumption that the earlier stages of the disease are missed in regular clinical monitoring (Zink 1986). However, some studies suggest the measuring of the rectal temperature as a reliable tool for monitoring (Cohen et al. 2002) and that fever appears more frequently in severely affected foals. Air- 
way sounds at the auscultation of lung and trachea are both described to occur in foals with pneumonia (Falcon 1985) but this is an insensitive method for early detection when used alone (Cohen et al. 2002).

Ultrasonography of the thorax is an effective diagnostic method to recognise pulmonary disorders and is often used as a screening technique on large horse-breeding farms. The scoring of pulmonary lesions according to the number of consolidations detected is helpful to determine the severity of pulmonary lesions (Slovis and McCracken 2005). A more precise scoring, including the number and the diameter of each pulmonary lesion detected, has been established (McCracken and Slovis 2009, Venner et al. 2014). Several studies have shown that it is a reliable method in diagnosing pneumonia (Rutenberg et al. 2017, Wetzig et al. 2019), even though ultrasound only shows lesions at the surface of the lung, while consolidations and abscesses without contact to the pleura cannot be detected.

Sulfadiazine-trimethoprim has been described as effective in treating pneumonia due to Strep. zoo. in foals (Fels et al. 2020, Hoffman 1993). The standard treatment for pneumonia with $R$. equi is rifampin in association with a macrolide. The use of rifampin and erythromycin reduced the mortality rate from 80 to $12 \%$ (Hillidge 1987). Different macrolides have been tested and azithromycin with rifampin is considered to be the gold standard for treating $R$. equi pneumonia in foals (Giguere 2017, Rutenberg et al. 2017). But tulathromycin (Rutenberg et al. 2017) as well as the combination of azithromycin and doxycyclin (Wetzig et al. 2019) also showed good efficacy.

\section{Material and Methods}

\section{Study population}

Foals included in this study were born in 2018 on a stud farm of Warmblood horses. Several studies in the past few years had shown both an endemic incidence of Strep. zoo. as well as $R$. equi, detected in both the lung tissues from post-mortem examination (Weimar 2006) and in tracheobronchial aspirates of foals with pneumonia (Hagist 2016, Hennig 2020). Parallel to the current study in 2018, every month tracheobronchial secretions samples were collected via endoscope in six to ten foals with ultrasonographic findings of pneumonia and were examined with microbiological culture. 53 foals of the current study were sampled at random and in 14 foals $R$. equi was isolated and in 40 foals Strep. zoo was detected.

The health status of all foals in the current study was closely monitored from birth until the age of 5.5 months, including weekly clinical examination, haematology and an ultrasonographic examination of the lung.

\section{Monitoring: clinical examination}

The habitus of the foal, measuring of the rectal temperature, auscultation of the lungs and the trachea, nasal discharge, mandibular lymph nodes, umbilical and scrotal hernia, and possible injuries were part of the clinical examination of each foal.

This study foccussed on the rectal temperature and the auscultation of lung and trachea. The temperature was increased when it was above $39.0^{\circ} \mathrm{C}$. The auscultation of the lung was aberrant when bronchovesicular sounds were increased and wheezes or crackles were heard. Râles and rattling were abnormal findings at auscultation of the trachea.

Method to define and detect the severity of pneumonia: ultrasonography of the lung

A portable unit (Esaote Tringa Linear, Milano, Italy) with a 7.5 $\mathrm{MHz}$ linear transducer was used to scan the surface of the lung. Both sides of the thorax were drenched with $99 \%$ alcohol to provide a better connection. The findings were immediately noted on forms, where each consolidation was registered: the precise localisation (right and left lung, number of the intercostal space, the dorsal part, the middle part or the ventral part of the lung) and the diameter in $\mathrm{cm}$ were noted. The size of irregular abscesses was evaluated by measuring the narrowest and widest diameter and taking the average of the two values. At the end of each ultrasonographic examination, the diameter of all consolidations of the foal were added together and the outcome specified as an "abscess score" in cm for each examination day. The abscess score was considered as a marker for the severity of the pulmonary disorder.

\section{Study design and inclusion criteria}

Foals with an abscess score of $5 \mathrm{~cm}$ or above were included in this study and divided into four groups each with different abscess scores and treatment. The parameters evaluated in the current study were the incidence of fever, the findings of the auscultation of lung and trachea, and the severity of the pulmonary disorder determined by means of ultrasonographical examination. The data were collected from the day of diagnosis (examination day $1=E D 1$ ) and two following examinations (ED 2 and 3), each one week apart.

A total of 465 foals were included in this study; the allocation and treatment of groups 1 to 4 are presented in Table 1. If the abscess score of foals with small pulmonary lesions (group 1: foals with no treatment) increased above $10 \mathrm{~cm}$, they were treated with the respective therapy and switched to groups 2, 3 or 4 of foals with mild to severe pneumonia according of the extent of the abscess score. If a foal with mild to severe pneumonia showed worsening of signs during treatment, the drugs were changed. The choice of antibiotics complied with the level of the abscess score; for example in a foal with a worsening of the abscess score above $15 \mathrm{~cm}$ rifampin and tulathromycin was chosen, and if the abscess score increased with more than $20 \mathrm{~cm}$ rifampin and azithromycin was chosen (dosages and route of administration see tab. 1). If the abscess score increased above $25 \mathrm{~cm}$ rifampin and gamithromycin was administered. Sulfadiazine-trimethoprim was added to rifampin and azithromycin or gamithromycin when increasing numbers of comet tails were noticed. 
The treatment was stopped, when not more than two consolidations with a diameter of $0.5 \mathrm{~cm}$ were found at sonography of the lung, thus, the abscess score of $1 \mathrm{~cm}$ or smaller was detected.

\section{Data and analysis}

Data of the clinical examination are used from the day of diagnosis and the following two weeks (ED 1 to 3).

The Statistical Analysis System for Windows SAS (Version 7.1) was used to analyse the data. The level of significance was set at $p<0.05$. The normal distribution of the data was tested with the Shapiro-Wilk test. The Wilcoxon two-sample test and the Kruskal-Wallis test were used to compare the incidence of fever and findings of auscultation between groups and with the abscess score. The occurrence of the three signs and the combined number of signs in foals for severity and the need for treatment change were tested with table analysis, the exact test after Fisher and the chi-squared test. The analysis of the age at the day of diagnosis between groups and the need for a change of treatment were done with one-way ANOVA and the Ryan-Einot-Gabriel-Welsch test. The correlation of age and abscess score was tested with Spearman's correlation analysis.

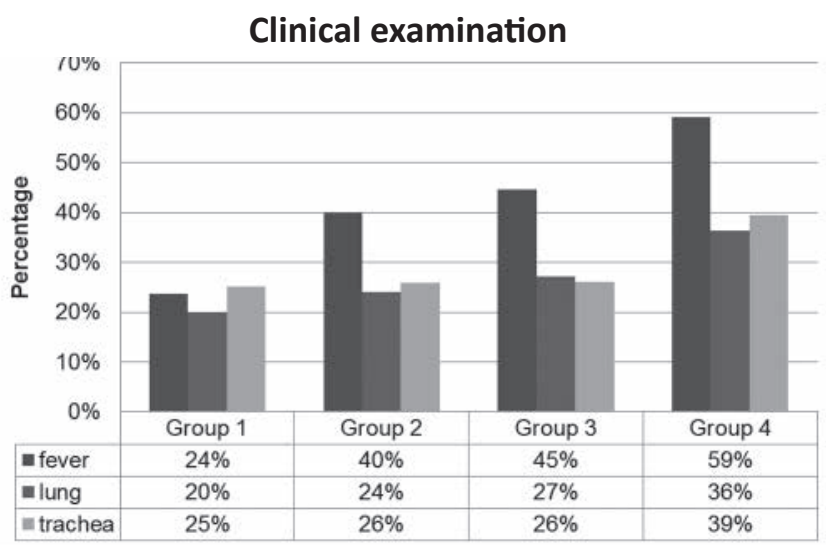

Fig. 1 Percentage of foals with abnormalities of body temperature and auscultation of lung and trachea for each group; Group $1=$ abscess score $5-9.5 \mathrm{~cm}(\mathrm{n}=135)$; Group 2 = abscess score 10$14.5 \mathrm{~cm}(\mathrm{n}=221)$; Group $3=$ abscess score $15-19.5 \mathrm{~cm}(\mathrm{n}=92)$; Group 4 =abscess score $>20 \mathrm{~cm}(\mathrm{n}=66) \quad$ | Prozentzahl von Fohlen mit Abweichungen der Körperinnentemperatur und Lungensowie Tracheaauskultation für jede Gruppe; Gruppe $1=$ Abszess Score 5-9,5 cm ( $\mathrm{n}=135)$; Gruppe 2 =Abszess Score 10-14,5 cm $(n=221)$; Gruppe $3=$ Abszess Score 15-19,5cm ( $n=92)$; Gruppe $4=$ Abszess Score über $20 \mathrm{~cm}(n=66)$

\section{Results}

Findings of the clinical examination and the severity of the disease at diagnosis of pneumonia

A total of 135 foals with an average age of 103 days $( \pm 30$ days) and small pulmonary lesions were included in group 1, 221 foals with a mild pneumonia and an average age of 102 days ( \pm 31 days) in group 2, and 92 foals with a moderate pneumonia and an average age of 106 days ( \pm 30 days) in group 3. Group 4 consisted of 66 foals with severe pneumonia and an average age of 105 days ( \pm 31 days).

In group 1, 36.3\% of the foals with small pulmonary lesions showed a worsening of the abscess score and immediately received treatment according to the abscess score. Of the foals with mild pneumonia (group 2) $16.4 \%$ needed a change of treatment, of the foals with moderate pneumonia (group 3) $3 \%$ and of foals with severe pneumonia (group 4) 9\% needed a change of treatment.

The percentage of foals with fever or findings at auscultation of lung and trachea at the day of diagnosis differed between the groups (Fig. 1).

A total of $23.7 \%$ of the foals with small pulmonary lesions (group 1) and $40 \%$ with mild pneumonia (group 2) had fever. A total of $44.6 \%$ of the foals with moderate pneumonia and $59.1 \%$ with severe pneumonia had fever at diagnosis. If fever was compared between the groups, foals with small pulmonary lesions (group 1) had fever significantly less frequently compared with the more affected foals $(p<0.0001$ to $p<0.0074$ ). The foals with severe pneumonia (group 4) had fever significantly more often than any of the less affected foals $(p<0.0001$ to $p<0.05)$.

The findings at auscultation of the lung in foals with small pulmonary lesions, mild and moderate pneumonia (groups 1, 2 and 3) were found in about 20 to $27.2 \%$ of the foals; the highest rate was found in foals with severe pneumonia (group 4) with $36.4 \%$. Findings at auscultation of the trachea occurred in the same manner as those at auscultation of the lung. The incidence of findings at auscultation of the lung and trachea increased from small to high with the increasing severity of the pneumonia. The incidence of findings of the auscultation of lung $(p<0.0123)$ and trachea $(p<0.0178)$ only differed significantly between foals with small pulmonary lesions (group 1) and those with severe pneumonia (group 4).

Table 1 Number of foals per group, abscess score at day of diagnosis and treatment; Group 1 = small pulmonary lesions; Group 2 = mild pneumonia; Group 3=moderate pneumonia; Group 4 =severe pneumonia | Anzahl der Fohlen pro Gruppe, Abszess Score am Tag der Diagnose und die Behandlung; Gruppe 1 = kleine pulmonale Läsionen; Gruppe 2 = milde Pneumonie; Gruppe 3 = mittelgradige Pneumonie; Gruppe 4 = hochgradige Pneumonie

\begin{tabular}{|c|c|c|c|}
\hline & Number of foals & Abscess score $(\mathrm{cm})$ & Treatment \\
\hline Group 1 & 135 & $5-9.5$ & No treatment \\
\hline Group 2 & 221 & $10-14.5$ & Sulfadiazine-trimethoprim ( $30 \mathrm{mg} / \mathrm{kg}$ p.o., q $12 \mathrm{~h}$ ) \\
\hline Group 3 & 92 & $15-19.5$ & $\begin{array}{l}\text { Rifampin (10 mg } / \mathrm{kg} \text { p.o., q } 24 \mathrm{~h}) \text { and } \\
\text { Tulathromycin }(2.5 \mathrm{mg} / \mathrm{kg} \text { i.m., once a week) }\end{array}$ \\
\hline Group 4 & 66 & $>20$ & $\begin{array}{l}\text { Rifampin }(10 \mathrm{mg} / \mathrm{kg} \text { p.o., q } 24 \mathrm{~h}) \text { and } \\
\text { Azithromycin (10 mg/kg i.mq q } 24 \mathrm{~h})\end{array}$ \\
\hline
\end{tabular}


The correlation between fever and the abscess score was highly significant in all foals $(p<0.0001)$ at the day of diagnosis. The abscess score was higher in foals with fever than in those without fever. The correlation between the findings of the auscultation of the lung and the abscess score was significant $(p<0.0049)$. There was no correlation between the findings of the auscultation of the trachea and the abscess score $(p<0.0950)$.

Findings of the clinical examination at diagnosis and later need of change of treatment

Foals with mild to severe pneumonia that needed a change of treatment later had fever $(p<0.0001)$ or findings at auscultation of lung $(p<0.002)$ and trachea $(p<0.0001)$ significantly more frequently than foals that recovered with the first treatment protocol (e.g. fever; Fig. 2).

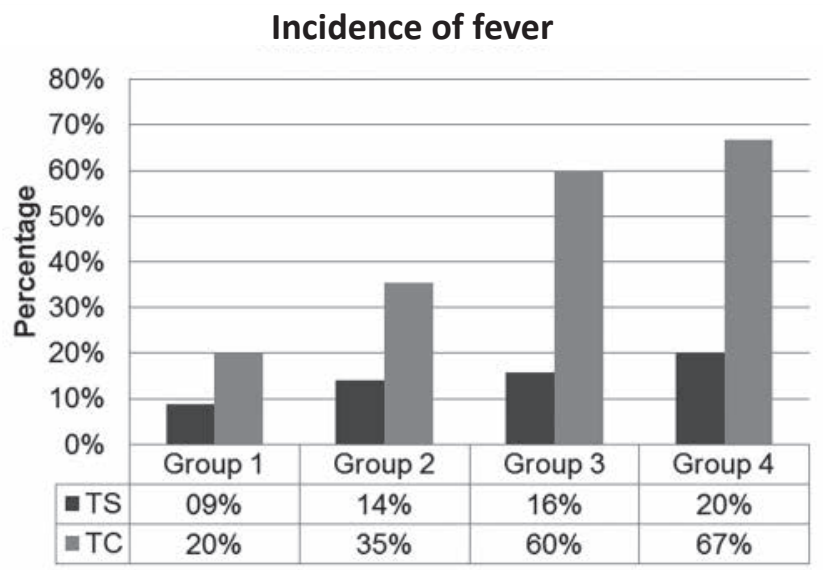

Fig. 2 Incidence of fever divided in foals with and without change of treatment; TS = first treatment successful; TC $=$ change of treatment necessary; Group $1=$ abscess score $5-9.5 \mathrm{~cm}$ $(n=135) ; \quad G r o u p \quad 2=$ abscess score $10-14.5 \mathrm{~cm} \quad(n=221)$; Group 3 = abscess score 15-19.5 cm ( $=92)$; Group $4=$ abscess score $>20 \mathrm{~cm}(\mathrm{n}=66) \quad$ Vorkommen von Fieber bei Fohlen mit und ohne Therapieumstellung; TS = Erfolg mit der ersten Therapie; $T C=$ notwendige Therapieumstellung; Gruppe $1=$ Abszess Score 5-9,5 cm ( $=135)$; Gruppe 2 =Abszess Score 10-14,5cm $(n=221)$; Gruppe $3=$ Abszess Score 15-19,5 cm ( $n=92)$; Gruppe 4 =Abszess Score über $20 \mathrm{~cm}(n=66)$
Clinical findings during the treatment of foals with pneumonia of different severity

Fever at diagnosis was significantly $(p<0.0001)$ more common for all foals compared to the subsequent examinations (Fig. 3). Findings at auscultation of the lung reduced significantly in foals with mild and severe pneumonia (group 2 and 4) from the first to the second examination, while the findings at auscultation of the trachea decreased significantly in foals with mild, moderate and severe pneumonia (group 2, 3 and 4) from the first to the second examination (one week after start of treatment).

Number of abnormalities per foal in comparison to the severity of pneumonia

Considering that one foal could have more than one sign, the occurrence of clinical findings at diagnosis in all groups was compared (Fig. 4). A total of 37 (6.6\%) foals had all three clinical findings: fever and findings at auscultation of trachea and lung. Two of the three clinical findings were shown by 104 foals $(18.5 \%)$ of all groups. One of the three clinical findings was found in 210 foals (37.4\%). None of these three clinical findings were observed in 211 foals (37.5\%).

While $48.9 \%$ of the foals with small pulmonary lesions (group 1) showed none of the three clinical findings, the percentage of the more severely affected foals with no symptoms (19.7\%) was considerably smaller. The fraction of foals with one of the three clinical findings was similar between all groups, ranging from 34.8 to $40.3 \%$. Two of the three clinical findings were shown twice as often in foals with moderate and severe pneumonia than in those which were mildly affected. All three signs were most frequent in severely affected foals (group 4; Fig. 5).

The foals that healed with the first choice of treatment and those that needed a change of treatment were separated for the following analysis. Significantly more (60.9\%) of the foals which had a change of treatment showed one clinical finding during the examination period than in foals without change of treatment $(35.7 \% ; p<0.0001)$. Moreover, at diagnosis, considerably more foals with treatment change had two of the three signs, whereas more foals that healed with the first choice showed no clinical finding (Fig. 6). Foals with a change of treat-

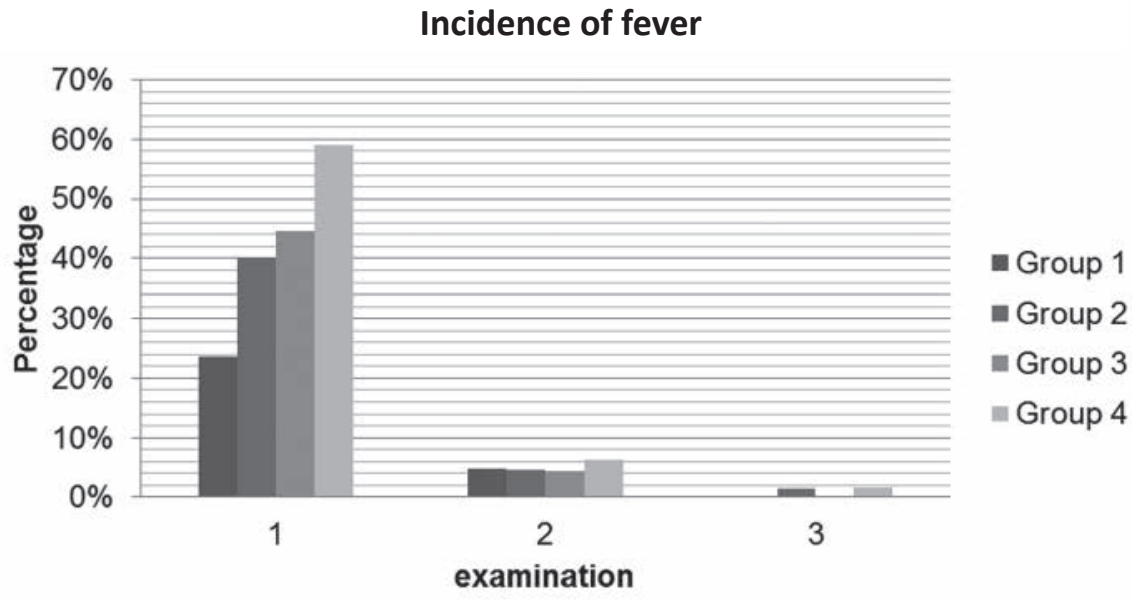

Fig. 3 Incidence of fever in foals with pneumonia (in \%) at diagnosis and in the following two examinations (weekly interval); Group $1=$ abscess score $5-9.5 \mathrm{~cm}$ $(n=135)$; Group 2=abscess score 10 $14.5 \mathrm{~cm}(\mathrm{n}=221)$; Group $3=$ abscess score $15-19.5 \mathrm{~cm} \quad(\mathrm{n}=92) ; \quad$ Group $4=$ abscess score $>20 \mathrm{~cm}(\mathrm{n}=66) \quad$ Vorkommen von Fieber bei Fohlen mit Pneumonie (in \%) bei der Diagnose und den beiden darauffolgenden Untersuchungen (wöchentlicher Abstand); Gruppe 1=Abszess Score 5-9,5 cm $(n=135) ;$ Gruppe $2=$ Abszess Score 10 14,5 cm $(n=221) ;$ Gruppe $3=$ Abszess Score 15-19,5cm ( $\mathrm{n}=92) ;$ Gruppe $4=$ Abszess Score über $20 \mathrm{~cm}(n=66)$ 
ment had a significantly higher number of signs $(p<0.0001)$ than foals that healed with the first treatment protocol.

Foals with no clinical findings had a lower abscess score than the foals that showed one, two or all three clinical findings (Table 2). The difference of the abscess score was significant $(p<0.0001$ to $p=0.03)$.

Correlation between the severity of the pneumonia and the age of the foals at diagnosis

The average age of the foals at diagnosis, 102 to 107 days (Median: 110 days; 25\%: 74.3-84.5 days; 75\%: 124-128 days), was similar for all foals of all groups. Only the foals that needed a change of treatment were significantly younger $(p<0.0001$; Fig. 7), with an average age of 80 days (Median: 71.5 days; $25 \%$ : 57.5 days; $75 \%$ : 100 days).

There was no correlation between the age at diagnosis and the abscess score. When only the foals with a change of treat-

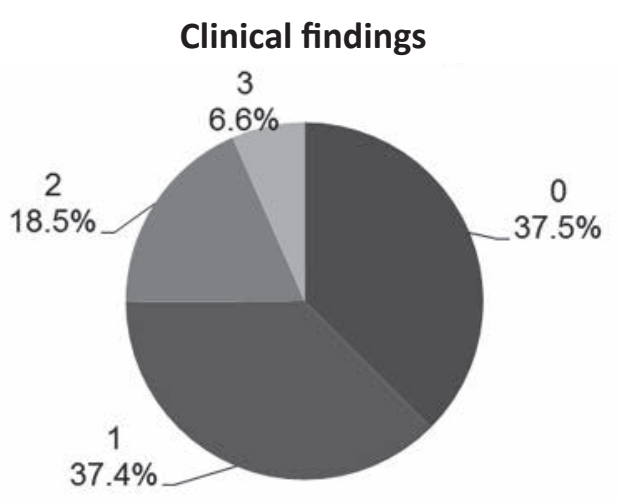

Fig. 4 Clinical findings at diagnosis: percentage of all foals with no (0), one (1), two (2) or three (3) signs | Anzahl klinischer Befunde bei Diagnose: Prozentsatz aller Fohlen mit keinem (0), einem (1), zwei (2) oder drei (3) Befunden

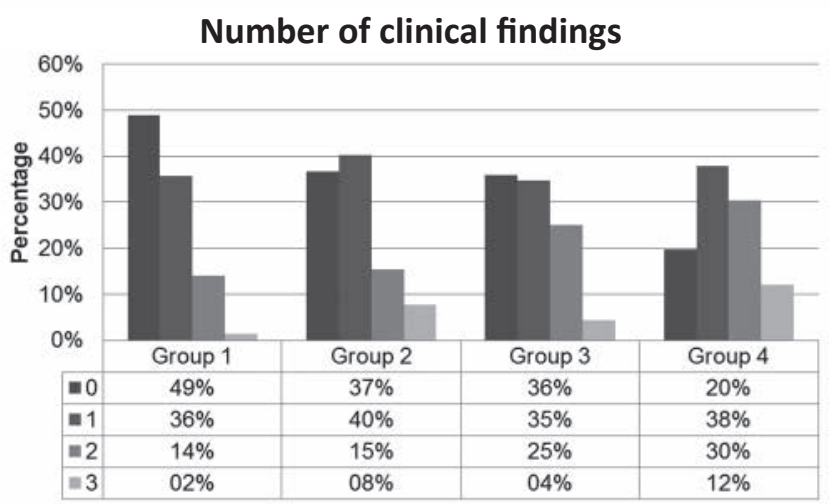

Fig. 5 Number of clinical findings in foals (in \%) with no (0), one (1), two (2) or three (3) signs; Group $1=$ abscess score 5-9.5 cm ( $n=135)$; Group $2=$ abscess score 10-14.5 cm $(n=221)$; Group $3=$ abscess score 15-19.5 cm ( $n=92)$; Group $4=$ abscess score $>20 \mathrm{~cm}(n=66)$ I Anzahl auffälliger klinischer Befunde in Fohlen (in \%) geteilt in keine (0), einen (1), zwei (2) und drei (3) Befunde; Gruppe $1=$ Abszess Score 5-9,5 cm ( $n=135)$; Gruppe $2=$ Abszess Score 10-14,5cm $(n=221)$; Gruppe $3=$ Abszess Score 15-19,5cm ( $n=92)$; Gruppe $4=$ Abszess Score über $20 \mathrm{~cm}(n=66)$ ment were analysed, age at diagnosis and abscess score correlated significantly $(r=-0.43 ; p<0.0001)$.

\section{Discussion}

The subject of this study was to describe and analyse specific clinical findings of the examination of foals with pneumonia. The focus was on the incidence of clinical findings in relation to the severity of the pneumonia and the need for a change of treatment. Additionally, the age distribution, the abscess score and a possible worsening of pneumonia later were analysed. The clinical signs of pneumonia have been investigated for many years. Most research concluded that the result of a clinical examination is not reliable to diagnose pulmonary disorders in foals (Thomé et al. 2018). When foals show clinical signs, the majority of those patients have pulmonary lesions that suggest a chronic course (Cohen 2014, Martens et al. 1982).

Additionally to clinical findings, further examinations, such as blood evaluation, radiography and ultrasonography of the

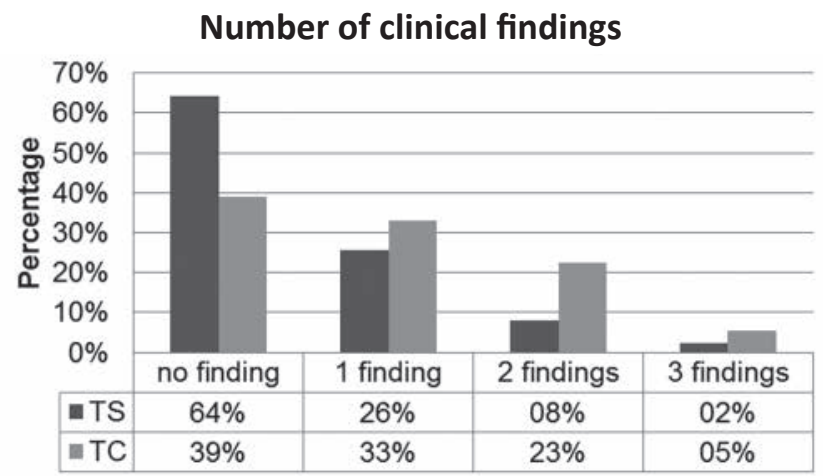

Fig. 6 Number of clinical findings (in \%) associated with the success of treatment (TS; $n=417$ ) and with the need for treatment change (TC; $\mathrm{n}=94) \quad \mid \quad$ Anzahl von auffälligen klinischen Befunden (in \%) im Zusammenhang mit dem Therapieerfolg (TS; $n=417$ ) und der Notwendigkeit einer Therapieumstellung (TC; $n=94)$

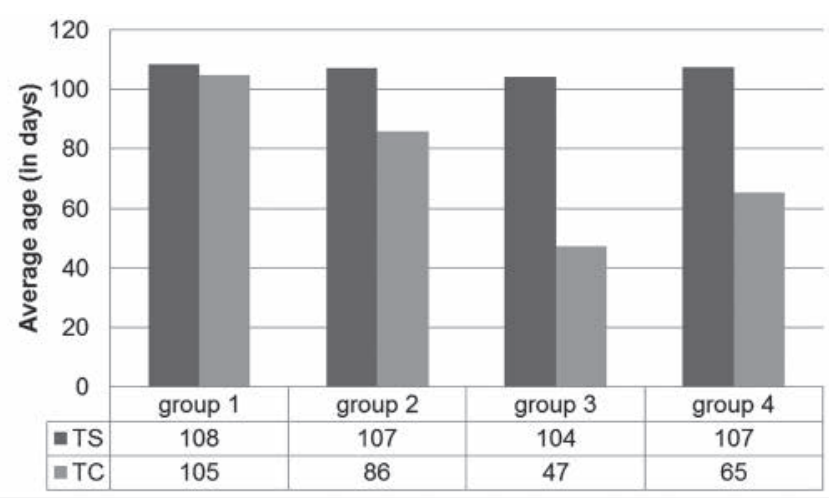

Fig. 7 Average age (in days) at diagnosis; TS = success with the first treatment; $\mathrm{TC}=$ change of treatment; group $1=$ small pulmonary lesions $(n=135)$; group $2=$ mild pneumonia $(n=221)$; group $3=\bmod$ erate pneumonia $(n=92)$; group $4=$ severe pneumonia $(n=66)$ Durchschnittliches Alter (in Tagen) bei Diagnose; TS =Erfolg mit der ersten Therapie; TC = notwendige Therapieumstellung; Gruppe 1 = kleine pulmonale Läsionen $(n=135)$; Gruppe 2 = geringgradige Pneumonie $(n=221)$; Gruppe $3=$ mittelgradige Pneumonie $(n=92)$; Gruppe 4 = hochgradige Pneumonie $(n=66)$ 
lung, were added in a screening program in order to diagnose pneumonia early in foals (Cohen et al. 2000, Venner and Klug 2005).

The most commonly described clinical signs are fever, airway sounds, an elevated respiratory frequency, lethargy, cough, nasal discharge and changes of the mandibular lymph nodes (Giguere et al. 2011, Prescott et al. 1989, Rajagopalan 1936). In the current study, the validity of specific clinical parameters, such as fever and airway sounds, for the diagnosis and classification of severity of pneumonia was analysed. Fever is the parameter most frequently mentioned and is one of the first findings observed in foals with pneumonia (Cohen 2014, Giguere 2001, Zink 1986). The validity of the increased body temperature regarding the severity of the pneumonia is not finally determined. Some studies claim that fever does not correlate with clinically and subclinically diseased foals (Althaus 2004) or with the pulmonary findings at ultrasonographic examination (Thomé et al. 2018). Whereas another author showed a significant correlation of the incidence of fever and the severity of the pneumonia (Falcon 1985). The current study showed that foals of a group with more severe pneumonia had an fever significantly more often than foals with mild pneumonia. Fever could be a warning signal for worsening of pneumonia, because significant more foals with a change of treatment had fever at diagnosis, than foals that healed with the first treatment.

The auscultation of lung and trachea is not a reliable method for early detection of pneumonia. This is due to the fact that pathological findings can rarely be found in the beginning of pneumonia (Cohen et al. 2002, Martens et al. 1982) or there is no correlation between airway sounds and the incidence of pneumonia (Falcon 1985, Genetzky 1984, Piltz 2004). Increased airway sounds caused by mucopurulent discharge appear in advanced cases of pneumonia in combination with a raised rectal temperature (Muscatello et al. 2007). In the current study, abnormal findings at auscultation were more frequent in severely affected foals compared to mildly sick foals.

Additionally abnormal findings at auscultation were found significantly more often in foals that needed a change of treatment than in those that healed with the first treatment. The auscultation of the lung and trachea at diagnosis could be a sign that worsening of pneumonia is possible.

A number of different findings can be detected during the development of pneumonia in foals (Prescott et al. 1989), there-

\footnotetext{
Table 2 Abscess score at diagnosis of pneumonia for the foals with no, one, two or three clinical findings; different superscript letters indicate a significant difference $(p<0.05) \quad \mid$ Abszess Score bei der Diagnose "Pneumonie" von Fohlen mit keinem, einem, zwei oder drei auffälligen klinischen Befunden; unterschiedliche hochgestellte Buchstaben weisen auf einen signifikanten Unterschied hin $(p<0,05)$
}

\begin{tabular}{cc}
\hline & $\begin{array}{c}\text { Abscess score }(\mathrm{cm}) \text { at diagnosis } \\
\text { (standard deviation) }\end{array}$ \\
\hline 0 clinical findings & $11.9^{\mathrm{a}}( \pm 4.9)$ \\
1 clinical finding & $13.7^{\mathrm{b}}( \pm 5.3)$ \\
2 clinical findings & $15.5^{\mathrm{c}}( \pm 6.4)$ \\
3 clinical findings & $16.8^{\mathrm{c}}( \pm 5.9)$ \\
\hline
\end{tabular}

fore, the current study evaluated the number and combination of abnormal findings as well. More than $37 \%$ of the foals with pulmonary findings at sonography showed no clinical signs. Even $20 \%$ of foals with severe lesions of the lung showed no abnormal findings at clinical examination. This confirms the inferiority of the clinical examination for early diagnosis, because too many foals are not detected despite severe pulmonary lesions at ultrasonography. On the other hand, this is not true in the later course of the pneumonia. The present results show that in foals with a high abscess score had significantly more clinical findings. Thus, it can be concluded that the number of clinical findings correlates to the severity of the pneumonia.

When foals with and without changes of treatment were compared, significantly more foals that needed a change of therapy had at least one of the three clinical signs. By contrast, foals without a change of treatment showed more frequently no abnormal finding. Therefore, a higher number of abnormal clinical findings in foals can indicate a worsening of the pneumonia.

It was already assumed almost 40 years ago that younger foals are more susceptible to pneumonia because the titre of maternal antibodies declines and the foals' own immune systems are still immature (Barton and Hughes 1980, Muscatello 2012). Considerable differences of the age at diagnosis have been reported in different studies. A higher predisposition from the second to fourth month was described (Barton and Hughes 1980, Falcon 1985), while others stated a period from the first to second (Prescott et al. 1989, Sippel 1968) or third month of life (Passamonti et al. 2015, Rajagopalan 1936, Thomé et al. 2018, Venner et al. 2012). Some studies stated that the age at the diagnosis of pneumonia correlates with severity (Sanz et al. 2013) or that clinically ill foals are older (Althaus 2004). The majority of the foals (62 to $72 \%$ of the different groups) in this current study were older than three months, while the average age was from 102 to 107 days, independent of the severity of pulmonary findings. Thus, the current study shows no significant correlation between the age and the severity of the pneumonia. This matches with a study from 2006 that showed no significant correlation between age and the necessity of treatment (Gravert 2006).

If only the foals with a change of treatment were observed, they were with an average age of 80 days at diagnosis significantly younger than the foals that healed with the first treatment (104 days). That confirms the statement of earlier studies (Venner et al. 2013, Venner et al. 2012), whereby younger foals need a change of therapy significantly more often. Therefore, especially younger foals should be carefully monitored during treatment in order to evaluate if the pneumonia is responsive to the treatment or if a change of drugs is necessary.

It must be emphasised, that in each foal with pneumonia the treatment needs to be chosen considering the isolation of pathogens from airway samples. As the resistogram is not usable in cases of $R$. equi as the in vitro sensitivity is not transferable to in vivo situation in intra cellular pathogens. In a breeding farm with endemic rhodococcosis it is compulsory to sample sick foals regularly to identify the pathogens and make the proper choice of antiinfective drugs. 


\section{Conclusion}

In conclusion, the three clinical signs analysed correlate with the severity of the pneumonia. Fever and findings at auscultation of the lung and trachea can be signal that the pulmonary findings might deteriorate during treatment. Therefore it is important to evaluate the success of therapy in foal with pneumonia. The body temperature especially can be a good method for monitoring or screening, even if it is not as reliable as ultrasound examination. When the ultrasonographic examination of all foals is not possible for financial or management reasons, clinical signs can help to select ill foals for further examination. Admittedly, the risk remains that even severely diseased foals can be missed because they appear healthy at clinical examination.

The severity of the pneumonia does not correlate with the foal's age, only the risk is higher in younger foals that the chosen therapy might not be sufficient. Therefore, the course of the disease should be closely monitored in younger foals in order to change the treatment protocol adequately.

\section{References}

Althaus O. (2004) Ultrasonography of the lung: an aid for early diagnosis of the Rhodococcus equi pneumonia of the foal. Diss. Med. Vet. Hannover

Barton M. D., Hughes K. L. (1980) Corynebacterium equi: a review. Vet. Bull. 50, 65-80

Cohen N. (2014) R. equi foal pneumonia. Vet. Clin. Equine 30, 609-622; DOI 10.1016/i.cveq.2014.08.010

Cohen N., Chaffin K., Martens J. G. (2002) How to prevent and control pneumonia caused by R. equi at affected farms. Am. Assoc. Equine Pract. Proc. 48, 295-299

Cohen N., Chaffin K., Martens R. J. (2000) Control and prevention of Rhodococcus equi pneumonia in foals. Comp. Cont. Educ. Pract. Vet .22, 1062-1070

Credner N. (2014) Comparative study of the effectiveness of tulathromycin in treatment of foals with pneumonia. Diss Med. Vet. Hannover

Falcon J. (1985) Clinical and radiographic findings in Corynebacterium equi pneumonia of foals. J. Am. Vet. Med. Assoc. 186, 593-598

Fels J., Lankenfeld A., Rohn K., Venner M. (2020) Study of the development of ultrasonographic findings of the lung of foals with pneumonia. Pferdeheilkunde 36, 537-546. DOI: 10.21836/ PEM20200606.

Genetzky R. M. (1984) Rhodococcus equi infection in foals. Mod. Vet. Pract. 65, 787-790

Giguere S. (2001) Rhodococcus equi pneumonia. Am. Assoc. Equine Pract. Proc. 47, 456-467

Giguere S. (2017) Treatment of infections caused bei R. equi. Vet. Clin. Equine 33, 67-85. DOI: 10.1016/j.cveg.2016.11.002.

Giguere S., Cohen N. D., Chaffin M. K., Hines S. A., Hondalus M. K., Prescott J. F., Slovis N. M. (2011) Rhodococcus equi: clinical manifestations, virulence, and immunity. J. Vet. Intern. Med. 25, 1221-1230. DOI: 10.1111/j.1939-1676.2011.00804.x.

Giguere S., Prescott J. F. (1997) Clinical manifestation, diagnosis, treatment and prevention of Rhodococcus equi infections in foals. Vet. Microbiol. 56, 313-334; DOI 10.1016/s0378$1135(97) 00099-0$

Gravert I. (2006) About the development of early recognized pulmonary abscesses. Diss. Med. Vet. Hannover

Hagist C. (2016) Genotyping of Rhosdococcus equi strains from Germany isolated in foals and other animals. Diss. Med. Vet. Hannover
Hartung K. (2018) Auswertung der Equinen-Sektionen im Institut für Veterinär-Pathologie der Universität Leipzig und Dresden von 1890 bis 2013, Universität Leipzig

Hennig M. (2020) Detection of Rhodococcus equi in tracheobronchial secretion and faeces of foals with pneumonia. Diss. Med. Vet. Hannover

Hillidge C. J. (1987) Use of erythromycin-rifampicin combination in treatment of Rhodococcus equi pneumonia. Vet. Microbiol. 14, 337-342; DOI 10.1016/0378-1135(87)90121-0

Hoffman A. (1993) Microbiologic changes during antimicrobial treatment and rate of relapse of distal respiratory tract infections in foals. Am. J. Vet. Res. 54, 1608-1614

Lavoie J. P., Fiset, L., Laverty, S. (1994) Review of 40 cases of lung abscesses in foals and adult horses. Equine Vet. J. 26, 348-352; DOI 10.1111/i.2042-3306.1994.tb04401.x

Lorenz N., Homuth M., Venner M., Strutzberg-Minder K. (2006) Bedeutende virale und bakterielle Atemwegserreger des Pferde und deren diagnostischer Nachweis. Pferdeheilkunde 22, 746-756; DOI 10.21836/PEM20060601

Martens R. J., Fiske R. A., Renshaw H. W. (1982) Experimental subacut foal pneumonia induced by aerosol administration of Corynebacterium equi. Equine Vet. J. 14, 111-116; DOI 10.1111/ i.2042-3306. 1982.tb02359.x.

McCracken J. L., Slovis N. M. (2009) Use of the thoracic ultrasound for prevention of Rhodococcus equi pneumonia on endemic farms. Am. Assoc. Equie Pract. Proc. 55, 38-44

Muscatello G. (2012) Rhodococcus equi pneumonia in the foal part 1: pathogenesis and epidemiology. Vet. J. 192, 20-26; DOI 10.1016/i.tvil.2011.08.014

Muscatello G., Leadon D. P., Klay M., Ocampo-Sosa A., Lewis D. A., Fogarty U., Buckley T., Gilkerson J. R., Meijer W. G., Vazquez-Boland J. A. (2007) Rhodococcus equi infection in foals: the science of 'rattles'. Equine Vet. J. 39, 470-478; DOI $10.2746 / 042516407 \times 209217$

Ohnesorge B., Trötschel C., Deegen E. (1998) Bestimmung von Totraum und exspiratorischem Mischluftvolumen zur Diagnostik chronischer Lungenerkrankung beim Pferd. Pferdeheilkunde 14, 450-455; DOI 10.21836/PEM19980602

Passamonti F., Vardi D. M., Stefanetti V., Marenzoni M. L., Prato S., Cevese P., Coletti M., Pepe M., Casagrande Proietti P., Olea-Popelka F. (2015) Rhodococcus equi pneumonia in foals: an assessment of the early diagnostic value of serum amyloid $A$ and plasma fibrinogen concentrations in equine clinical practice. Vet. J. 203, 211-218; DOI 10.1016/i.tvjl.2014.08.033

Piltz K. (2004) Compared treatment of R. equi-pneumonia in foals with azithromycin and rifampicin in combination with erythromycin or trimethoprim/sulfadiazin. Diss. Med. Vet. Hannover

Prescott J. F., Machang'u R., Kwiecien J., Delaney K. (1989) Prevention of foal mortality due to Rhodococcus equi pneumonia on an endemically affected farm. Can. Vet. J. 30, 871-875

Rajagopalan V. R. (1936) Pneumonia in foals due to Corynebacterium equi. Ind. J. Vet. Sci. Anim. Husb. 7, 38-53

Rutenberg D., Venner M., Giguere S. (2017) Efficacy of tulathromycin for the treatment of foals with mild to moderate bronchopneumonia. J. Vet. Intern. Med. 31, 901-906; DOI 10.1111/jvim.14717

Sanz M., Loynachan A., Sun L., Oliveira A., Breheny P., Horohov D. W. (2013) The effect of bacterial dose and foal age at challenge on Rhodococcus equi infection. Vet. Microbiol. 167, 623-631; DOI 10.1016/i.vetmic.2013.09.018

Sippel W. L. (1968) Corynebacterium infection in foals: etiology, pathogenesis and laboratory diagnosis. J. Am. Vet. Med. Assoc. 153, 1610-1613

Slovis N. M., McCracken J. L., Mundy G. (2005) How to use thoracic ultrasound to screen foal for $R$. equi at affected farms. Am. Assoc. Equine Pract. Proc. 51 st Annual Convention, 274-278

Takai S., Ohkura H., Watanabe Y., Tsubaki S. (1986) Quantitative aspects of fecal Rhodococcus (Corynebacterium) equi in foals. J. Clin. Microbiol. 23, 794-796; DOI 10.1128/JCM.23.4.794796. 1986 
Thomé R., Rohn K., Venner M. (2018) Clinical and haematological parameters for the early diagnosis of pneumonia in foals. Pferdeheilkunde 34, 260-266; DOl 10.21836/pem20180307

Timoney J. F. (2004) The pathogenic equine streptococci. Vet. Res. 35, 397-409; DOI 10.1051/vetres:2004025

Venner M., Astheimer K., Laemmer M., Giguere S. (2013) Efficacy of mass antimicrobial treatment of foals with subclinical pulmonary abscesses associated with Rhodococcus equi. J. Vet. Intern. Med. 27, 171-176; DOI 10.1111/jvim.12030

Venner M., Klug E. (2005) R. equi pneumonia in foals: diagnosis and therapy. Pferde Spiegel, 155-158

Venner M., Roediger A., Laemmer M., Giguere S. (2012) Failure of antimicrobial therapy to accelerate spontaneous healing of subclinical pulmonary abscesses on a farm with endemic infections caused by Rhodococcus equi. Vet. J. 192, 293-298; DOI 10.1016/i.tvil.201 1.07.004
Venner M., Walther S. M., Münzer B., Stadler P. (2014) Diagnostic of pulmonary abscesses in foals - comparison of sonographic and radiographic examination. Pferdeheilkunde 30, 561-566; DOI 10.21836/PEM20140507

Weimar B.-M. (2006) Lung abscesses of foals: clinical, sonographic, endoskopic, pathomorphologic and microbiologic findings. Diss. Med. Vet. Hannover

Wetzig M., Venner M., Giguere S. (2019) Efficacy of the combination of doxycycline and azithromycin for the treatment of foals with mild to moderate bronchopneumonia. Equine Vet. J. 52, 613-619; DOI 10.1111/evj.13211

Zink M. C. (1986) Corynebacterium equi infections in horses, 19581984: a review of 131 cases. Can. Vet. J. 27, 213-217 